\title{
Checking Behaviours, Prospective Memory and Executive Functions
}

\author{
Lorna Elise Palmer, Kevin Durkin and Sinéad M. Rhodes \\ School of Psychological Sciences and Health, University of Strathclyde, Glasgow, United Kingdom
}

\begin{abstract}
Explanations implicating memory in the causes and severity of checking symptoms have focused primarily on retrospective memory, and relatively little attention has been paid to prospective memory. Limited research has examined the relationship between prospective memory and executive functions. We assessed whether impairments in prospective memory and executive function predict checking symptoms in a sample of 106 adults. Checking symptoms were assessed using the Padua Inventory Washington State University Revision (PI-WSUR). All participants completed the prospective memory questionnaire (PMQ) and four computerised executive function tasks from the CANTAB, measuring inhibition, planning, attention set-shifting and working memory. Prospective memory and inhibition predicted checking symptom severity. Importantly, there were no correlations between internally cued prospective memory and inhibition or between prospective memory aiding strategies and inhibition. These variables appear to have an independent role in checking. The current findings highlight prospective memory and inhibition as key contributors to the checking symptom profile and provide the first evidence that these cognitive processes may independently contribute to checking symptoms. These findings have implications for a model in which memory performance is thought to be secondary to impairments in executive functions.
\end{abstract}

Keywords: checking compulsions, prospective memory, executive function, memory deficit hypothesis, CANTAB

Obsessive compulsive disorder (OCD) is a chronic and debilitating disorder characterised by intrusive thoughts or images (obsessions) and by repetitive behaviours or recurrent mental acts (compulsions; Stein, 2002). Although there are different types of compulsive behaviours, one of the most common is checking (Henderson \& Pollard, 1988). Individuals with checking compulsions have recurrent uncertainties about whether they have performed or completed particular acts (such as locking their car or closing a window) and they return repeatedly to ensure that they have done so.

Uncovering the causes of checking compulsions is challenging. Considerable research has documented impaired neuropsychological function in individuals with OCD (Chamberlain, Blackwell, Fineberg, Robbins, \& Sahakian, 2005; Kuelz, Hohagen, \& Voderholzer, 2004). On present evidence, it seems unlikely that there is a single underlying factor. Furthermore, the heterogeneity of symptoms among individuals with OCD indicates that it would be advantageous to identify the etiology of each subtype. Focusing here on the checking subtype, we review literature indicating that memory impairment is an important variable and that there are strong reasons to

\footnotetext{
Address for correspondence: Sinéad M. Rhodes, School of Psychological Sciences and Health, University of Strathclyde, Glasgow, G1 1,QE, UK.

E-mail: sinead.rhodes@strath.ac.uk
}

Behaviour Change |Volume 32|Number 2|2015।pp. 74-92 IC) The Author(s) 2015. This is an Open Access article, distributed under the terms of the Creative Commons Attribution licence (http://creativecommons.org/licenses/by/4.0/), which permits unrestricted re-use, distribution, and reproduction in any medium, provided the original work is properly cited. 
suspect that executive functions play a role. To date, the respective contributions of these factors to predicting checking behaviour have not been examined in the same sample. In this study, we conduct such an investigation.

\section{Memory and Checking}

Because checking reflects the individual's uncertainty as to whether a specific action has been undertaken, an early hypothesis was that deficits in memory underlie the phenomenon. However, the evidence has been somewhat mixed. Some areas of memory (such as verbal memory) appear to be unimpaired in individuals with OCD (Olley, Malhi, \& Sachdev, 2007). Reviewers of the literature (Müller \& Roberts, 2005; Olley et al., 2007) have concluded that OCD does appear to be associated with impairments in memory related to behavioural actions but that the evidence is unclear with respect to whether the problems are primarily in memory itself or reflect the impact of symptoms on functioning and confidence in memory and/or broader organisational difficulties.

Previous research has tended to examine retrospective memory (Cuttler \& Graf, 2007, 2009). Cuttler and Graf $(2007,2008,2009)$ argued that prospective memory may be particularly compromised in checkers. Prospective memory relates to actions that are to be performed in the future, such as remembering that one has to pay a bill at the end of each month or keeping in mind that one must turn the cooker off after preparing dinner. Cuttler and Graf reasoned that individuals with checking compulsions may have difficulties deactivating mental plans after completing them, or may fail to remember specific actions that they have completed, or may be aware of their chronic problems with prospective memory and thus worry about the risk of future failure; any or all of these could promote checking to obtain reassurance that all is as it should be. Checking, therefore, may be a compensatory mechanism for prospective memory failures.

\section{Prospective Memory}

Prospective memory impairments, based on subjective measures, have been indicated in a study by Cuttler and Graf (2007). Individuals with high checking symptoms reported significantly more failures in long-term episodic prospective memory, shortterm habitual prospective memory and internally cued prospective memory than did those with medium checking symptoms. Episodic prospective memory tasks relate to those where to-be-remembered information is not held in conscious awareness and intended actions are performed infrequently, or on a one-off basis (e.g., collecting your sibling from the station in 2 weeks' time). Habitual prospective memory tasks involve repeated, regular performance of the same plan (e.g., picking up the house keys before leaving). Internally cued prospective memory relates to performing tasks where no external cue/reminder is provided to perform already planned tasks (e.g., remembering to pay a bill on time). Individuals with high checking symptoms also reported using more prospective memory aiding strategies than low checkers (e.g., writing reminder lists). Checkers' self-reports, then, indicate that they perceive themselves as having difficulties with several aspects of prospective memory.

Objective evidence of prospective memory impairments was also shown in medium and high checkers, using an event-based prospective memory task (Cuttler \& Graf, 2007). This involved remembering to perform an action under specific conditions when an external cue occurred; for example, requesting the return of a personal 
belonging when a specific spoken cue was given (Cuttler \& Graf, 2007). Similar results were reported by Cuttler and Graf (2008). In contrast, low, medium and high checkers were not impaired on a time-based prospective memory task that involved remembering to perform an action at a particular time or after a specific time period; for example, reminding the experimenter to make a phone call in 30 minutes (Cuttler \& Graf, 2007). Checking occurs when uncertainty cannot be removed or reduced using specific strategies. The occurrence of a relevant cue is unpredictable in event-based remembering. Hence, uncertainty is likely to be high and contribute to repetitive checking behaviours. Time-based tasks, however, provide individuals with a clear cue for when a task should be completed and thus uncertainty is reduced. As event but not time-based prospective memory impairments have been reported in checkers, the current study will focus on event-based prospective remembering (Cuttler \& Graf, 2007).

Cuttler and Graf's $(2007,2008)$ studies were conducted with participants with subclinical levels of checking compulsions, on the grounds that evidence in support of a prospective memory account in this population would suggest an even stronger effect in a clinical sample. This reasoning was largely borne out in a subsequent study by Harris, Vaccaro, Jones, and Boots (2010), who investigated prospective memory in a clinical sample using the same subjective and objective tasks employed by Cuttler and Graf $(2007,2008)$. Harris et al. indicated that OCD-checkers were less accurate than controls on the event-based prospective memory task. A difference was not observed, however, in subjective memory reports made by the OCD and comparison control group. The discrepancy between the studies may have arisen because the clinical manifestation of checking symptoms is related to a less accurate perception of one's own prospective memory performance. Harris et al. found that the OCD-checkers, although performing less well on the event-based task, had greater confidence in their prospective memory than did the controls. Taken together, these studies indicate subjective and objective evidence of prospective memory impairments in samples of checkers.

\section{Executive Function and Checking}

Executive function is an umbrella term denoting higher order strategic processes, such as inhibition, planning, attention set shifting and working memory, known to be critical in the control of behaviour. If an individual is engaging in repetitive, redundant activity, failing to adjust his or her behaviour after completing a task, and is unable to recall relevant past actions with confidence, then an encompassing explanation of his or her difficulties may relate to prefrontal systems and executive functions that these systems support (Burgess, Veitch, de Lacy Costello, \& Shallice, 2000; Martin, Kliegel, \& McDaniel, 2003; McDaniel, Glisky, Rubin, Guynn, \& Routhieaux, 1999).

76 Executive function impairments have been reported in several studies investigating OCD (Bannon, Gonsalvez, Croft, \& Boyce, 2006; Chamberlain et al., 2005; Taner, Bakar, \& Oner, 2011).

From a theoretical perspective, a common mechanism is thought to underlie all executive function processes but different aspects of executive function are clearly separable (Diamond, 2013; Miyake et al., 2000). Although theoretical explanations have placed different weighting on executive functions, most implicate inhibition, working memory and attention set-shifting as core executive function processes (Miyake et al., 
2000) and higher order functions such as planning and problem solving (Diamond, 2013).

The most consistent evidence for executive dysfunction with respect to OCD indicates a deficit in inhibition, which is the ability to suppress irrelevant or interfering stimuli (Abramovitch, Dar, Schweiger, \& Hermesh, 2011; Aycicegi, Dinn, Harris, \& Erkmen, 2003; Bannon, Gonsalvez, Croft, \& Boyce, 2002; Bohne, Keuthen, TuschenCaffier, \& Wilhelm, 2005; Chamberlain, Fineberg, Blackwell, Robbins, \& Sahakian, 2006; Chamberlain, Fineberg, Menzies et al., 2007; Morein-Zamir et al., 2010; Page et al., 2009; Penades et al., 2007; Sottocorno, Martoni, Galimberti, Fadda, \& Bellodi, 2011). If an individual finds it difficult to inhibit a pre-potent plan ('Must close the bathroom window'), then, despite having undertaken the relevant action, this distracting cognition could reoccur and prompt checking. The small numbers of studies addressing this possibility in individuals with checking compulsions have found evidence of inhibitory control deficits in checkers (Omori et al., 2007; Van der Linden, Ceschi, Zermatten, Dunker, \& Perroud, 2005)

Planning impairments may contribute to greater checking arising from a difficulty in organising the execution of actions effectively within memory. Planning impairments have been implicated in OCD, using tasks such as the Stockings of Cambridge and Tower of Hanoi (Cavedini, Cisima, Riboldi, D'Annucci, \& Bellodi, 2001; Cavedini, Zorzi, Piccinni, Cavallini, \& Bellodi, 2010; Chamberlain, Fineberg, Blackwell et al., 2007; Nielen \& Den Boer, 2003; van den Heuvel et al., 2005). Also see Purcell, Maruff, Kyrios, and Pantelis (1998a, 1998b) and Veale, Sahakian, Owen, and Marks (1996) for null results in this respect. Findings, therefore, are mixed, and the issue of whether planning impairments contribute to and maintain checking symptoms is unresolved. As far as we are aware, two studies have been conducted to investigate planning abilities in individuals with predominant checking symptoms (Chamberlain, Fineberg, Blackwell et al., 2007; Nedeljkovic et al., 2009). Chamberlian, Fineberg, Blackwell et al. (2007) reported planning deficits in a group of individuals with predominant checking and washing symptoms when the task was more difficult. Furthermore, Nedeljkovic et al. (2009) reported that checkers and those in a mixed symptom group had poorer performance on initial movement times relating to cognitive speed on the Stockings of Cambridge planning task compared to washers. As far as the researchers are aware, however, a specific planning accuracy measure (problems solved in minimum number of moves) was not included in this analysis.

Given the perseverative nature of checking symptoms, it is plausible that checkers may encounter difficulties in moving flexibly from one task or action to another (i.e., attention set-shifting). The evidence to date is inconsistent. Some studies have found evidence of an attentional set-shifting deficit in participants with OCD (Okasha et al., 2000; Veale et al., 1996), but others have not (Moritz et al., 2002; Nielen \& Den Boer, 2003). Surprisingly little research has investigated set-shifting in checkers. Exceptions are the work of Goodwin and Sher (1992) and Omori et al. (2007). Goodwin and Sher reported that frequent checkers performed significantly worse than non-checkers and Omori et al. reported set-shifting deficits in clinical checkers compared to washers.

Working memory impairments may result in individuals being unsure whether or not a task was completed, resulting in compulsive checking behaviours. Research in those with OCD symptoms has produced inconsistent findings, with some studies finding evidence of working memory impairments (Chamberlain, Fineberg, Blackwell et al., 2007; Purcell et al., 1998a, 1998b) and others not (Dittrich, Johansen, Fineberg, \& Landro, 2011; Morein-Zamir et al., 2010; Nielen \& Den Boer, 2003). There is 
support, however, from two studies of Spatial Working Memory (SWM) impairments in checkers (Jaafari et al., 2013; Nedeljkovic et al., 2009). An interesting possibility is that an orientation to high levels of checking can itself impact on the efficiency of working memory, as demonstrated experimentally by Harkin and Kessler (2009, 2011).

There is some evidence, then, to implicate inhibition, planning, attention setshifting and working memory in OCD. The relative strength, however, of these executive function impairments in predicting checking symptoms has not been assessed in a single study.

\section{Prospective Memory and Executive Function}

If, as the evidence so far suggests, both prospective memory and executive function are implicated in the behaviours of checkers, the question arises as to the nature of the relationship between these variables. In studies not related to OCD, it has been proposed that prospective memory performance may be related to executive functions (Fuermaier et al., 2013; Kliegel, Eschen, \& Thöne-Otto, 2004; McNerney \& West, 2007; Schnitzspahn, Stahl, Zeintl, Kaller, \& Kliegel, 2013; Smith \& Bayen, 2005; West \& Craik, 2001; West, Scolaro, \& Bailey, 2011). Most theoretical accounts propose that prospective memory at some stage requires resource demanding processes (Marsh \& Hicks, 1998; McDaniel \& Einstein, 2000; Smith, 2003; Smith \& Bayen, 2004).

Supportive of theoretical accounts, studies have indicated that if prospective memory cues occur while an individual is engaged in other activity, he or she has to inhibit that activity to meet the predetermined obligation (Schnitzspahn et al., 2013; West $\&$ Craik, 2001). Shimamura, Janowsky, and Squire (1991) proposed that prospective memory and inhibition share commonalities. It is possible therefore that there may be a relationship between inhibition and prospective memory. Limited research, however, has been conducted to investigate this relationship. Henry, Rendell, Kliegel, and Altgassen (2007) examined the extent to which prospective memory impairments are secondary to other cognitive functions in a sample of individuals diagnosed with schizophrenia. Results from this study revealed that both prospective memory and inhibition deficits are evident in schizophrenia. Furthermore, after controlling for cognitive and executive function (inhibition) and retrospective memory, significant impairments were still evident in prospective memory in the group with schizophrenia. This finding suggests that prospective memory may represent a distinct deficit in individuals with schizophrenia, beyond inhibitory dysfunction. This may also apply to checkers and thus will be investigated, while also examining the relationship between prospective memory, checking symptoms and inhibitory functioning.

Studies investigating prospective memory and planning in other cognitively impaired groups, such as individuals with traumatic brain injury (Kliegel et al., 2004) and participants with attention deficit hyperactivity disorder (Fuermaier et al., 2013), are supportive of the hypothesis that there may be a relationship between prospective memory performance and executive functions. Kliegel et al. (2004) reported that individuals with deficits in executive functioning performed worse than healthy controls on a prospective memory task. Similarly, Fuermaier et al. (2013) indicated that impairments in prospective memory in adults with attention deficit hyperactivity disorder related to planning impairments. To complete a prospective memory intention, an individual is required to plan an effective strategy and then execute this plan 
when particular environmental cues are present. Impairments in planning may result in reduced prospective memory performance.

Theoretical accounts of prospective memory suggest that shifting attention between the ongoing task and evaluation of responses in the environment is imperative to successful prospective memory performance. Empirical evidence has supported this proposal (McNerney \& West, 2007; West et al., 2011). Prospective memory may also require an intended action to be held in mind while monitoring the environment for potential cues in order to execute a required response successfully, indicating a relationship between working memory and prospective memory performance (Smith \& Bayen, 2005; West \& Craik, 2001). The current study will also examine attention set-shifting and working memory and their relationship with prospective memory in checkers.

\section{The Present Study}

The current study set out to investigate the role of episodic prospective memory, habitual prospective memory, internally cued prospective memory, and prospective memory aiding strategies in checking. We know that prospective memory is related to checking (Cuttler \& Graf, 2007, 2008; Harris et al., 2010); therefore, it was expected that deficits in each of these components of prospective memory would predict checking severity. The role of executive functions in checkers was also examined. OCD studies in general implicate inhibition, planning, attention set-shifting and working memory. Evidence for the role of each of these aspects of executive function in relation to checking is very limited (Chamberlain, Fineberg, Blackwell et al., 2007; Goodwin \& Sher, 1992; Jaafari et al., 2013; Nedeljkovic et al., 2009; Omori et al., 2007; Van der Linden et al., 2005). Despite theoretical reasons to posit a relationship between prospective memory and executive function, it appears that no study has examined both sets of variables together in the same sample of checkers. Identifying the relative importance of each of these variables and the relationship between them will contribute to our understanding of the causes of checking behaviour and the nature of the disorder.

\section{Method}

\section{Participants and Design}

Prospective memory and executive functions were investigated in relation to checking symptoms using a sample that included subclinical participants. Spinella (2005) has shown that subclinical OCD symptoms are relatively common in non-clinical populations, arguing that they share common neurobiological substrates with clinical OCD. The inclusion of a sample with subclinical participants should reduce the impact of medication (Cuttler \& Graf, 2007). No participants in the final sample reported using medication. A total sample of 122 participants was recruited from a student population. Individuals reporting a previous clinical diagnosis of OCD (seven participants) were excluded from the analyses. Due to computer problems, the SST did not run correctly for nine participants, leaving 106 participants for the final analysis $(66 \%$ female and $34 \%$ male). The sample had a mean age of $23.56(S D=6.37)$ years. To ensure our sample included individuals with a range of symptom scores on checking characteristics, following Cuttler and Graf (2007), we displayed some advertisements that called explicitly for participants with checking behaviours and others where checking behaviours were not mentioned. Ethical approval was granted 
by the appropriate departmental ethics committee and participants received either course credits or a small financial compensation in return for their participation.

\section{Measures}

Checking symptoms. The Padua Inventory was originally developed (Sanavio, 1988) to provide a self-report measure of the symptoms of OCD. The present study employed a revised version (Padua Inventory Washington State University Revision PI-WSUR) developed by Burns, Keorge, Formea, and Sternberger (1996) that distinguishes between worry, obsessions and compulsions. This revised inventory contains 39 items describing common obsessive compulsive behaviours (e.g., 'I tend to keep on checking things more often than necessary'). For each item, participants use a 5-point Likert type response to indicate their degree of disturbance caused by each behaviour. The response labels are marked: not at all (0), a little (1), quite a lot (2), a lot (3), very much (4). The inventory contains five subscales, each of which measures different obsessive compulsive concerns: contamination obsessions and washing compulsions, dressing/grooming compulsions, checking compulsions, obsessional thoughts of harm to self/others, and obsessional impulses to harm self/others. 'Checking' symptoms were calculated by adding up individuals' ratings for the items contained within the checking subscale (Items 14-23). Symptom scores on the checking subscale ranged from zero to 40; a higher score indicates greater checking symptoms. The checking subscale had good internal reliability with a Cronbach's alpha value of $\alpha=0.91$ in the current study.

Prospective memory. The Prospective Memory Questionnaire (PMQ; Hannon, Adams, Harrington, FriesDias, \& Gipson, 1995) is a standardised self-report instrument designed for measuring prospective memory. The scale consists of 52 items examining different prospective memory failures (e.g., I forgot to return a phone call) and memory aiding techniques (e.g., I write myself reminder notes). Participants are asked to rate how often he or she experience each failure or use each memory aiding technique in a specific time period (e.g., a week, month or year). For each item, participants use a 9-point Likert-type response, ranging from not applicable (0), never (1) to $4 / 6$ times a week/month/year (9). The questionnaire contains four subscales: (1) longterm episodic tasks, (2) short-term habitual tasks, (3) internally cued tasks, and (4) prospective memory aiding strategies. Self-reported 'Prospective memory total' scores were calculated by adding responses on subscales 1-3 and response scores ranged from $0-342$. A higher score indicates more self-reported prospective memory failures. The PMQ had good internal reliability with a Cronbach's alpha value of $\alpha=0.92$ in the current study.

Executive function tasks. Participants performed a range of executive function tasks taken from the Cambridge Neuropsychological Test Automated Battery (CANTAB; www.camcog.com; Morris, Evendon, Sahakian, \& Robbins, 1987). The executive function tasks used were the Stop Signal Task (inhibition), Stockings of Cambridge task (planning), Intra-Dimensional/Extra-Dimensional task (attention set-shifting) and Spatial Working Memory task (working memory). The tasks have been used extensively in clinical OCD and healthy control samples (Chamberlain, Fineberg, Blackwell et al., 2007; Chamberlain, Fineberg, Menzies et al., 2007; Morein-Zamir et al., 2010; Nielen \& Den Boer, 2003; Purcell et al., 1998a, 1998b; Watkins et al., 
2005). One key outcome measure was chosen for each task with the components described below.

Inhibition: The Stop-Signal Task (SST) provides an assessment of response inhibition. The test consists of two parts and gives a measure of an individual's ability to inhibit a pre-potent response. In the first part, which involves training, participants are told to press the left-hand button when he or she see a left-pointing arrow and the right-hand button when he or she see a right-pointing arrow. In the second part, participants are told to continue pressing the buttons on the press pad when he or she see the arrows as before but, if they hear an auditory signal (a beep), they should withhold their response and not press the button. The stop-signal paradigm allows a sensitive estimate of inhibitory control. The key outcome measure was stop signal reaction time ('Inhibition') — an estimate of the length of time between the go stimulus and the stop stimulus at which the participant was able to successfully inhibit their response in the last half of the task (last $50 \%$ of trials - the processing time required to inhibit a pre-potent response). A higher response time on this measure indicates less inhibitory control.

Planning: The Stockings of Cambridge (SOC) task was derived from the Tower of Hanoi task (Shallice, 1982) and measures planning ability. Participants are required to move balls hanging in 'socks' to match a 'goal arrangement' and are told to think of these like snooker balls in pockets. The aim is to use the balls in the lower display to copy the pattern in the upper display. Participants are told that the problems can be solved in a certain 'minimum number of moves' - two, three, four or five moves - and this number is displayed on the side of the screen. In order to be successful, participants are required to plan out the full set of moves prior to executing a move. For each trial, a control condition is completed to enable estimates of 'movement times' in order to provide an estimate of planning times. The key measure on this task was the number of problems solved in the minimum number of moves ('planning'). A higher score on this measure indicates better planning abilities, with a minimum score of 0 and maximum score of 12 .

Attention set-shifting: The executive Intra-Dimensional/Extra-Dimensional (ID/ED) task assesses attention set-shifting, involving the executive function ability of shifting flexibly from focusing attention on one aspect of stimulus to another. The task measures a participant's ability to focus attention on specific attributes of compound stimuli (intra-dimensional stages) and to shift attention when required to a previously irrelevant stimulus dimension (extra-dimensional stages). There are nine stages in the task. At each stage, two different stimuli are presented (e.g., solid shapes). Participants are instructed to choose the stimulus he or she think is correct and they receive feedback. Once the participant correctly chooses the same stimuli over six trials the task moves to the next stage. The intra-dimensional stages involve shifting from one solid shape to another, whereas the executive extra-dimensional stages require shifting from one type of stimulus to another (solid shape to a line). The key measure on this task was the stage-reached score ('set-shifting'). A higher stage-reached score indicates higher performance for executive set-shifting and reversal.

Working memory: The Spatial Working Memory (SWM) task is a searching task that assesses working memory for spatial stimuli and requires participants to use mnemonic information to work towards a goal. Participants are asked to search through a spatial array of coloured boxes to collect blue tokens hidden behind the boxes. Participants must keep searching through all the boxes until he or she find the blue token. Ultimately, participants will find a blue token behind each of the 
boxes. Experimental trials commence with a four box search and the highest difficulty level involves eight box trials. Participants can use a (self-initiated) strategy to aid performance; for example, always starting at the top left of the array of boxes, moving across to bottom right. If a participant returns to a box where a token has already been found, this constitutes a between-search error ('spatial working memory') and this was the key outcome measure for this task. A higher between-search error on this measure indicates poorer spatial working memory.

\section{Procedure}

Before taking part in the study, participants provided informed written consent. In the experimental phase, participants completed the Padua Inventory first, followed by the PMQ. The executive function tasks were then completed and were presented on a high resolution colour monitor utilising a touch sensitive screen. The order of the executive function tasks was counterbalanced to mitigate any fatigue effects. Completing all components of the study required approximately one hour. Upon completing the final task, participants were given a debriefing form explaining the purpose of the study.

\section{Results}

Means and standard deviations of experimental measures and Pearson correlations between study measures are presented in Table 1. Prior to carrying out statistical analyses, the data were screened to determine whether statistical assumptions were met (Field, 2009; Tabachnick \& Fidell, 2007). Assumptions of linearity, normality and homogeneity of variance were met when residuals scatter plots were examined with checking as the dependent variable for all variables. Multicollinearity was not a problem as no predictor variables were highly correlated above 0.80 (Field, 2009).

A multiple linear regression analysis with checking score as the dependent variable was used to determine the independent predictors of checking symptoms. Only variables correlated with checking were entered into the regression model. Each of the remaining independent variables (long-term episodic prospective memory, shortterm habitual prospective memory, internally cued prospective memory, prospective memory aiding strategies and inhibition) were entered into the regression analysis to examine whether they predicted checking symptom severity. In a sample of 106 participants, the use of five key measures to test individual predictors was within the recommended guidelines for sufficient power to detect significant effects within a regression analysis (Tabachnick \& Fidell, 2007).

\section{Correlational Analyses}

Pearson's correlations revealed significant positive relationships between checking and each of the prospective memory subcategories. Higher self-reported checking symptoms were associated with higher reports of long-term episodic, short-term habitual and internally cued prospective memory failures. A significant positive relationship was shown between checking and prospective memory aiding strategies; higher checking symptoms were associated with greater use of strategies to aid prospective memory. A positive relationship was shown between checking and inhibition. Higher selfreported checking symptoms was associated with slower reaction times (higher scores) on the inhibitory task, indicating greater inhibitory impairment. A significant positive correlation was also shown between long-term episodic prospective memory failures 


\section{TABLE 1}

Means and Standard Deviations and Correlations for Key Measures

\begin{tabular}{|c|c|c|c|c|c|c|c|c|c|}
\hline & Mean $(S D)$ & 2. & 3. & 4. & 5. & 6. & 7. & 8. & 9. \\
\hline 1. Checking & $12.51(9.02)$ & $0.30^{* *}$ & $0.17^{*}$ & $0.40^{* * *}$ & $0.47^{* * *}$ & $0.21^{*}$ & 0.04 & 0.04 & -0.12 \\
\hline 2. Long-term episodic prospective memory & $37.37(16.14)$ & & $0.56^{* * *}$ & $0.72^{* * *}$ & $0.25^{* *}$ & -0.01 & -0.02 & $0.17^{*}$ & $-0.17^{*}$ \\
\hline 3. Short-term habitual prospective memory & $19.20(7.63)$ & & & $0.47^{* * *}$ & 0.08 & 0.00 & 0.00 & 0.07 & 0.00 \\
\hline 4. Internally cued prospective memory & $29.32(13.46)$ & & & & $0.37^{* * *}$ & -0.02 & 0.09 & 0.05 & 0.00 \\
\hline 5. Prospective memory aiding strategies & $59.25(25.54)$ & & & & & 0.09 & 0.03 & -0.02 & -0.11 \\
\hline 6.. Inhibition & $173.93(51.37)$ & & & & & & $0.17^{*}$ & -0.01 & 0.14 \\
\hline 7. Set-shifting & $8.65(0.73)$ & & & & & & & $-0.24^{* *}$ & $0.19^{*}$ \\
\hline 8. Spatial working memory & $13.06(12.29)$ & & & & & & & & $-0.56^{* * *}$ \\
\hline 9. Planning & $9.49(1.89)$ & & & & & & & & \\
\hline
\end{tabular}

Note: ${ }^{*} p<.05,{ }^{* *} p<.01,{ }^{* * *} p<.001$. 


\section{TABLE 2}

Standardised Regression Coefficients Predicting Checking Symptoms

\begin{tabular}{|c|c|c|c|c|c|c|}
\hline \multirow[b]{3}{*}{ Predictors } & \multicolumn{6}{|c|}{ Predicting checking } \\
\hline & \multirow[b]{2}{*}{ Beta } & \multicolumn{2}{|c|}{$95 \% \mathrm{Cl}$} & \multirow[b]{2}{*}{$S E \mathrm{~B}$} & \multirow[b]{2}{*}{ Standardised $\beta$} & \multirow[b]{2}{*}{$R^{2}$ Change } \\
\hline & & $\begin{array}{l}\text { Lower } \\
\text { bound }\end{array}$ & $\begin{array}{l}\text { Upper } \\
\text { bound }\end{array}$ & & & \\
\hline Constant & -6.04 & -13.12 & -1.05 & 3.57 & & \\
\hline $\begin{array}{l}\text { Long-term episodic } \\
\text { prospective memory }\end{array}$ & 0.17 & -0.13 & 0.16 & 0.07 & 0.03 & .09 \\
\hline $\begin{array}{l}\text { Short-term habitual } \\
\text { prospective memory }\end{array}$ & 0.14 & -0.22 & 0.25 & 0.12 & 0.01 & .00 \\
\hline $\begin{array}{l}\text { Internally cued } \\
\text { prospective memory }\end{array}$ & 0.17 & -0.00 & 0.33 & 0.08 & $0.25^{+}$ & .07 \\
\hline $\begin{array}{l}\text { Prospective memory } \\
\text { aiding strategies }\end{array}$ & 0.12 & 0.06 & 1.87 & 0.03 & $0.35^{* * *}$ & .12 \\
\hline Inhibition & 0.03 & 0.00 & 0.06 & 0.02 & $0.18^{*}$ & .03 \\
\hline
\end{tabular}

Note: ${ }^{*} p<.05,{ }^{* * *} p<.001,^{+}=.06$

and poorer spatial working memory. Similarly, higher scores for long-term episodic memory failures were associated with lower planning scores (reflecting a poorer ability to plan). There were significant correlations between some of the executive function measures (see Table 1).

\section{Linear Regression Analysis}

A multiple linear regression analysis was conducted with checking symptoms as the dependent variable. After entry of long-term episodic prospective memory, shortterm habitual prospective memory, internally cued prospective memory, prospective memory aiding strategies, and inhibition, a significant model emerged, $F(5,100)=$ $8.95, p<.001$. This model explained $28 \%$ of the variance in checking symptoms (adjusted $\left.R^{2}=.28\right)$. Table 2 reveals that prospective memory aiding strategies $(p<$ $.001)$ and inhibition $(p=.04)$ were independent predictors of checking symptoms. Internally cued prospective memory approached significance as a predictor of checking symptoms $(p=.06)$. Exploratory analyses revealed that when long-term episodic prospective memory was entered alone it was a significant predictor of checking symptoms, $F(1,104)=10.19, p=.002$, adjusted $R^{2}=.08$, Beta $=.30$; however, it no longer accounted for any unique variance when the other variables were entered into the model, suggesting potential suppressor effects. As no significant correlations were observed between prospective memory and inhibition, mediational analyses (see Figure 1) were not conducted.

\section{Discussion}

The current study set out to examine the predictive power of prospective memory and executive functions on checking symptom severity. Checking symptom severity was predicted by internally cued prospective memory and prospective memory aiding 


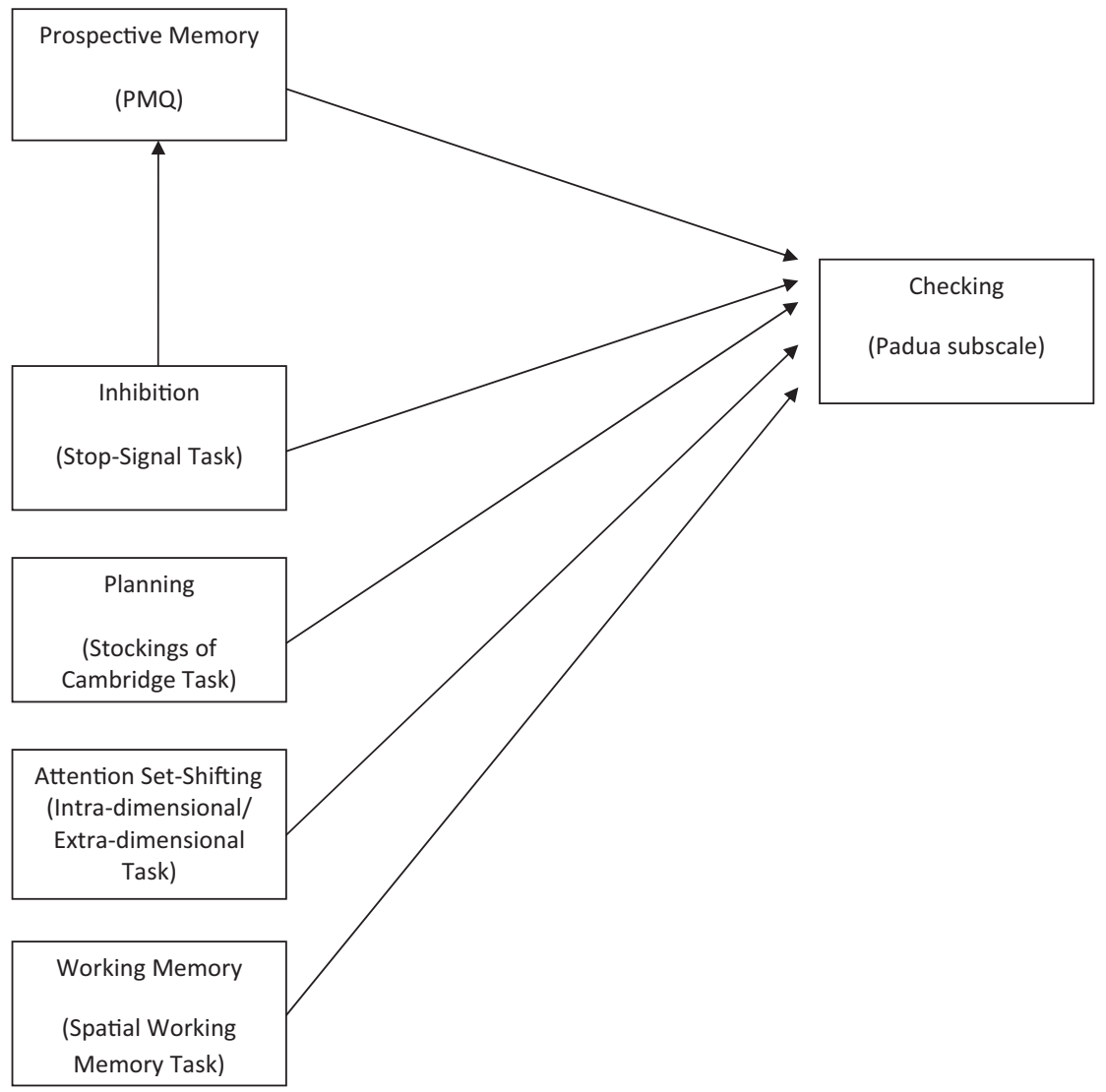

FIGURE 1

Proposed model of pathway

strategies. Specifically, higher internally cued prospective memory failures and higher prospective memory aiding strategies predicted higher checking symptoms. Long-term episodic prospective memory was a predictor of checking symptoms when entered alone, but was no longer a predictor when entered with other variables, suggesting that it may not be an independent predictor of checking symptoms. Previous reports of prospective memory deficits are, therefore, supported (Cuttler \& Graf, 2007, 2008). Inhibition also contributed to the prediction of checking severity. This finding is consistent with previous work (Omori et al., 2007; Van der Linden et al., 2005).

The relationship between prospective memory and inhibition was examined as they were both significant predictors of checking symptom severity. No correlations were observed between internally cued prospective memory and inhibition or between prospective memory aiding strategies and inhibition. These results suggest that each of the variables contribute independently to checking symptoms. The association was greatest between prospective memory aiding strategies and checking symptoms (as assessed by the standardised beta and $R^{2}$ change), suggesting that this aspect of prospective memory provides a greater contribution to the frequency of checking 
symptoms. Internally cued prospective memory provided the next greatest contribution, followed by inhibition.

The prospective memory data reported here are in line with previous work (Cuttler \& Graf, 2007, 2008). Cuttler and Graf indicated that individuals with high checking symptoms had more long-term episodic, short-term habitual and internally cued prospective memory impairments, and used more prospective memory aiding strategies. In the current study, higher internally cued prospective memory failures and prospective memory aiding strategies predicted higher checking symptoms when entered alone and when entered with other variables, indicating that they are independent predictors of checking. Long-term episodic prospective memory predicted checking symptoms when entered alone but not when entered into the model with other variables, implying that it is not an independent predictor of checking.

Short-term habitual prospective memory impairments, however, were not shown to predict checking symptoms in the current study. These memory impairments involve performing behaviours on a routine basis and it might be anticipated that problems in managing short-term routine tasks would be strongly linked to a perceived need to check; thus, this finding is surprising. This finding is contrary to work presented by Cuttler and Graf (2007). Differences in results may be due to the subjective assessment of prospective memory. Nonetheless, with both the current study and Cuttler and Graf (2007, 2008) reporting prospective memory deficits using self-report questionnaires, impairment in samples that are comprised of participants with subclinical checking symptoms is strongly indicated.

Current findings are incongruent with the findings of Harris et al. (2010), who indicated that OCD-checkers did not self-report prospective memory impairments. The current study and Cuttler and Graf $(2007,2008)$ used samples recruited from nonclinical settings while Harris et al. recruited participants from clinical settings. The differences between studies could be due to genuine differences in prospective memory abilities in non-clinical and clinical samples, or groups may differ in self-awareness and insight into their own characteristics. Despite these differences, it is important to recognise the accumulating evidence that subclinical checkers do perceive themselves as having problems in this respect (see Hermann, Sheets, Gruneberg, \& Torres, 2005, for evidence of the validity of self-reported memory failures, especially prospective memory failures).

The current study revealed that executive function impairments were not uniformly associated with checking symptom severity. Out of the executive functions measured, only inhibition was shown to be related to checking symptoms, with poorer inhibitory control predicting higher checking symptoms. Difficulties of individuals with this compulsion cannot, therefore, be explained in terms of a pervasive and unified deficit in executive function but relate to a specific dimension of cognitive regulation.

The current findings are consistent with those of Omori et al. (2007) and Van der Linden et al. (2005), who reported that checkers displayed significant inhibitory impairments. Similarly, previous reports of impaired inhibition when general OCD symptoms were measured are supported (Abramovitch et al., 2011; Chamberlain, Fineberg, Menzies et al., 2007; Morein-Zamir et al., 2010). Checkers may have difficulty in suppressing irrelevant information, including removing a completed task from their 'to do' list, and focusing on the task in hand, which could then trigger concerns and doubts about the behaviour being completed and thus subsequent compulsions to check. 
Planning ability was not shown to predict checking symptoms. The present findings are similar to those reported in clinical OCD samples (Purcell et al., 1998a, 1998b; Veale et al., 1996). The current findings, however, are contrary to some previous work, also with OCD samples (Cavedini et al., 2001; Cavedini et al., 2010; Chamberlain, Fineberg, Blackwell et al., 2007; Nielen \& Den Boer, 2003; van den Heuvel et al., 2005). Surprisingly, Nielen and Den Boer (2003) used the same planning outcome variable as the current study and Purcell et al. (1998a, 1998b), yet found evidence of planning impairments in a clinical sample. It is important to consider why there may be discrepancies in these findings when the same tasks were used. Both studies used clinical samples; however, compulsive behaviours were greater in the study conducted by Nielen and Den Boer in comparison to those in the Purcell et al. studies. A possible explanation for the contradictory findings may link to symptom severity, particularly since Nakao et al. (2009) indicated that severity may affect neuropsychological functioning.

Attentional flexibility was not shown to be a significant predictor of checking symptoms in the current study. Previous findings are, therefore, not supported (Goodwin \& Sher, 1992; Omori et al., 2007). It is difficult, however, to compare earlier findings with the current study, as attention-shifting was measured differently by Goodwin and Sher (1992) and Omori et al. (2007). The present findings are consistent with results from a previous study using a clinical sample (Nielen \& Den Boer, 2003). The role of attention set-shifting in the expression of OCD and, in particular, checking symptoms is an unresolved issue.

Working memory performance was not shown to predict checking symptoms in the current study. This is supportive of previous studies also using the CANTAB SWM task but in general OCD samples (Dittrich et al., 2011; Morein-Zamir et al., 2010; Nielen \& Den Boer, 2003). Nonetheless, the current findings are inconsistent with work presented by Jaafari et al. (2013) and Nedeljkovic et al. (2009), where working memory performance was shown to predict checking behaviours in clinical samples. The results are also contrary to research indicating poorer working memory performance in individuals clinically diagnosed with OCD (Chamberlain, Fineberg, Blackwell et al., 2007; Purcell et al., 1998a, 1998b). Conflicting findings in spatial working memory performance may be attributable to differences in severity and subtype (Nakao et al., 2009). It is also possible that some working memory tasks are more sensitive to the impairments of checkers (see Harkin \& Kessler, 2011).

Importantly, no relationship was shown between prospective memory subscales and inhibitory function. This is consistent with an argument advanced by McDaniel and Einstein (2000) that prospective memory involves automatic retrieval processes. The current results, however, are inconsistent with an argument developed by McDaniel and Einstein that preparatory processes are not automatic and should be influenced by executive functions. The current finding is also contrary to what was expected, based on previous literature (Martin et al., 2003; McNerney \& West, 2007; Salthouse, Berish, \& Siedlecki, 2004; Schnitzspahn et al., 2013; Smith \& Bayen, 2005; West \& Craik, 2001; West et al., 2011). It is difficult to compare these studies as both prospective memory and executive functions have been measured differently in varying populations. It has been proposed that a more complex prospective memory task theoretically demands the largest involvement of executive function processes (Martin et al., 2003; McNerney \& West, 2007). This proposal may help to explain why no relationships were observed between prospective memory measures and inhibition. 
Further research, therefore, should investigate the relationship between prospective memory and inhibition using a more complex objective prospective memory paradigm.

The lack of significant relationships between prospective memory and inhibition is supportive of research reported by Henry et al. (2007). Henry et al. reported that prospective memory deficits may present as an independent deficit in patients with schizophrenia. After controlling for executive function impairments, significant impairments were still evident in prospective memory in the group with schizophrenia (Henry et al.). The current findings indicate that prospective memory deficits that predict checking cannot be explained as secondary to impairments in executive functions.

Overall, internally cued prospective memory and prospective memory aiding strategies significantly predicted checking symptom severity in this study. Inhibition, planning, attention set-shifting and working memory were all examined in relation to checking symptoms but of these only inhibition was shown to predict checking severity. Correlational analyses showed that prospective memory and inhibition were independent predictors of checking severity. A clearer understanding of the range of cognitive impairments in participants with checking-like traits can potentially help us to improve the everyday functioning of individuals clinically diagnosed with the disorder. Identifying the difficulties that lead to the engagement of compulsive behaviours can contribute to therapeutic approaches aimed at reducing the behaviours.

\section{Acknowledgments}

This research was funded by the Economic and Social Research Council.

\section{References}

Abramovitch, A., Dar, R., Schweiger, A., \& Hermesh, H. (2011). Neuropsychological impairments and their association with obsessive-compulsive symptom severity in obsessive-compulsive disorder. Archives of Clinical Neuropsychology, 26, 364-376. doi:10.1093/arclin/acr022

Aycicegi, A., Dinn, W.M., Harris, C.L., \& Erkmen, H. (2003). Neuropsychological function in obsessive-compulsive disorder: Effects of comorbid conditions on task performance. European Psychiatry, 18, 241-248. doi:http://dx.doi.org/10.1016/S0924-9338(03)00065-8

Bannon, S., Gonsalvez, C.J., Croft, R.J., \& Boyce, P.M. (2002). Response inhibition deficits in obsessive-compulsive disorder. Psychiatry Research, 110, 165-174. doi:10.1016/s0165-1781(02)00104-x

Bannon, S., Gonsalvez, C.J., Croft, R.J., \& Boyce, P.M. (2006). Executive functions in obsessivecompulsive disorder: State or trait deficits? Australian and New Zealand Journal of Psychiatry, 40, 1031-1038. doi:10.1080/j.1440-1614.2006.01928.x

Bohne, A., Keuthen, N.J., Tuschen-Caffier, B., \& Wilhelm, S. (2005). Cognitive inhibition in trichotillomania and obsessive-compulsive disorder. Behaviour Research and Therapy, 43, 923942. doi:10.1016/j.brat.2004.06.014

Burgess, P.W., Veitch, E., de Lacy Costello, A., \& Shallice, T. (2000). The cognitive and neuroanatomical correlates of multitasking. Neuropsychologia, 38, 848-863.

Burns, G.L., Keortge, S.G., Formea, G.M., \& Sternberger, L.G. (1996). Revision of the padua inventory of obsessive compulsive disorder symptoms: Distinctions between worry, obsessions, and compulsions. Behaviour Research and Therapy, 34, 163-173. doi:10.1016/0005-7967(95)00035-6

Cavedini, P., Cisima, M., Riboldi, G., D’Annucci, A., \& Bellodi, L. (2001). A neuropsychological study of dissociation in cortical and subcortical functioning in obsessive-compulsive disorder by tower of hanoi task. Brain and Cognition, 46, 357-363. doi:10.1006/brcg.2001.1293 
Cavedini, P., Zorzi, C., Piccinni, M., Cavallini, M.C., \& Bellodi, L. (2010). Executive dysfunctions in obsessive-compulsive patients and unaffected relatives: Searching for a new intermediate phenotype. Biological Psychiatry, 67, 1178-1184. doi:10.1016/j.biopsych.2010.02.012

Chamberlain, S.R., Blackwell, A.D., Fineberg, N.A., Robbins, T.W., \& Sahakian, J. (2005). The neuropsychology of obsessive compulsive disorder: The importance of failures in cognitive and behavioural inhibition as candidate endophenotypic markers. Neuroscience and Biobehavioral Reviews, 29, 399-419. doi:10.1016/j.neubiorev.2004.11.006

Chamberlain, S.R., Fineberg, N.A., Blackwell, A.D., Clark, L., Robbins, T.W., \& Sahakian, B.J. (2007). A neuropsychological comparison of obsessive-compulsive disorder and trichotillomania. Neuropsychologia, 45, 654-662. doi:10.1016/j.neuropsychologia.2006.07.016

Chamberlain, S.R., Fineberg, N.A., Blackwell, A.D., Robbins, T.W., \& Sahakian, B.J. (2006). Motor inhibition and cognitive flexibility in obsessive-compulsive disorder and trichotillomania. American Journal of Psychiatry, 163, 1282-1284. doi:10.1176/appi.ajp.163.7.1282

Chamberlain, S.R., Fineberg, N.A., Menzies, L.A., Blackwell, A.D., Bullmore, E.T., Robbins, T.W., \& Sahakian, B.J. (2007). Impaired cognitive flexibility and motor inhibition in unaffected firstdegree relatives of patients with obsessive-compulsive disorder. American Journal of Psychiatry, 164, 335-338. doi:10.1176/appi.ajp.164.2.335

Cuttler, C., \& Graf, P. (2007). Sub-clinical compulsive checkers' prospective memory is impaired. Journal of Anxiety Disorders, 21, 338-352. doi:10.1016/j.janxdis.2006.06.001

Cuttler, C., \& Graf, P. (2008). Sub-clinical checking compulsions are related to impaired prospective memory independently of depression, anxiety and distractibility. Journal of Anxiety Disorders, 22, 642-654. doi:10.1016/j.janxdis.2007.06.003

Cuttler, C., \& Graf, P. (2009). Checking-in on the memory deficit and meta-memory deficit theories of compulsive checking. Clinical Psychology Review, 29, 393-409. doi:10.1016/j.cpr.2009.04.003

Diamond, A. (2013). Executive functions. Annual Review of Psychology, 64, 135-168. doi:10.1146/annurev-psych-113011-143750

Dittrich, W., Johansen, T., Fineberg, N., \& Landro, N.I. (2011). Cognitive performance and specific deficits in OCD symptom dimensions: II. Spatial memory and impaired recognition of visuospatial object locations. German Journal of Psychiatry, 14, 1-12.

Elliott, M.A., \& Ainsworth, K. (2012). Predicting university undergraduates' binge-drinking behavior: A comparative test of the one- and two-component theories of planned behavior. Addictive Behaviors, 37, 92-101. doi:10.1016/j.addbeh.2011.09.005

Field, A. (2009). Discovering statistics using SPSS (3rd ed.). London: Sage Publications.

Fuermaier, A. B. M., Tucha, L., Koerts, J., Aschenbrenner, S., Westermann, C., Weisbrod, M., ... Tucha, O. (2013). Complex prospective memory in adults with attention deficit hyperactivity disorder. PLoS ONE, 8, e58338. doi:10.1371/journal.pone.0058338

Goodwin, A.H., \& Sher, K.J. (1992). Deficits in set-shifting ability in nonclinical compulsive checkers. Journal of Psychopathology and Behavioral Assessment, 14, 81-92. doi:10.1007/bf00960093

Hannon, R., Adams, P., Harrington, S., FriesDias, C., \& Gipson, M.T. (1995). Effects of brain injury and age on prospective memory self-rating and performance. Rehabilitation Psychology, 40, 289-298. doi:10.1037/0090-5550.40.4.289

Harkin, B., \& Kessler, K. (2009). How checking breeds doubt: Reduced performance in a simple working memory task. Behaviour Research and Therapy, 47, 504-512. doi:10.1016/j.brat.2009.03.002

Harkin, B., \& Kessler, K. (2011). How checking as a cognitive style influences working memory performance. Applied Cognitive Psychology, 25, 219-228. doi:10.1002/acp.1666

Harris, L.M., Vaccaro, L., Jones, M.K., \& Boots, G.M. (2010). Evidence of impaired eventbased prospective memory in clinical obsessive-compulsive checking. Behaviour Change, 27, 84-92.

Henderson, J.G., \& Pollard, C.A. (1988). Three types of obsessive compulsive disorder in a community sample. Journal of Clinical Psychology, 44, 747-752. doi:10.1002/1097-4679(198809)44: $5<747::$ AID-JCLP2270440513>3.0.CO;2-2 
Henry, J.D., Rendell, P.G., Kliegel, M., \& Altgassen, M. (2007). Prospective memory in schizophrenia: Primary or secondary impairment? Schizophrenia Research, 95, 179-185. doi:http://dx.doi.org/10.1016/j.schres.2007.06.003

Hermann, D., Sheets, V., Gruneberg, M., \& Torres, R. (2005). Are self-reports of memory failure accurate? Applied Cognitive Psychology, 19, 821-841. doi:10.1002/acp.1125

Jaafari, N., Frasca, M., Rigalleau, F., Rachid, F., Gil, R., Olié, J.P., ... Vibert, N. (2013). Forgetting what you have checked: A link between working memory impairment and checking behaviors in obsessive-compulsive disorder. European Psychiatry, 28, 87-93. doi:http://dx.doi.org/10.1016/j.eurpsy.2011.07.001

Kliegel, M., Eschen, A., \& Thöne-Otto, A.I.T. (2004). Planning and realization of complex intentions in traumatic brain injury and normal aging. Brain and Cognition, 56, 43-54. doi:http://dx.doi.org/10.1016/j.bandc.2004.05.005

Kuelz, A.K., Hohagen, F., \& Voderholzer, U. (2004). Neuropsychological performance in obsessive-compulsive disorder: A critical review. Biological Psychology, 65, 185-236. doi: 10.1016/j.biopsycho.2003.07.007

Marsh, R.L., \& Hicks, J.L. (1998). Event-based prospective memory and executive control of working memory. Journal of Experimental Psychology: Learning, Memory and Cognition, 24, 336-349.

Martin, M., Kliegel, M., \& McDaniel, M.A. (2003). The involvement of executive functions in prospective memory performance of adults. International Journal of Psychology, 38, 195-206. doi:10.1080/00207590244000205

McDaniel, M.A., \& Einstein, G. O. (2000). Strategic and automatic processes in prospective memory retrieval: A multiprocess framework. Applied Cognitive Psychology, 14, S127-S144. doi:10.1002/acp.775

McDaniel, M.A., Glisky, E.L., Rubin, S.R., Guynn, M.J., \& Routhieaux, B.C. (1999). Prospective memory: A neuropsychological study. Neuropsychology, 13, 103-110.

McNerney, M.W., \& West, R. (2007). An imperfect relationship between prospective memory and the prospective interference effect. Memory and Cognition, 35, 275-282.

Miyake, A., Friedman, N.P., Emerson, M.J., Witzki, A.H., Howerter, A., \& Wager, T.D. (2000). The unity and diversity of executive functions and their contributions to complex 'frontal lobe' tasks: A latent variable analysis. Cognitive Psychology, 41, 49-100. doi:10.1006/cogp.1999.0734

Morein-Zamir, S., Craig, K.J., Ersche, K.D., Abbott, S., Muller, U., Fineberg, N.A., ... Robbins, T.W. (2010). Impaired visuospatial associative memory and attention in obsessive compulsive disorder but no evidence for differential dopaminergic modulation. Psychopharmacology, 212, 357-367. doi:10.1007/s00213-010-1963-z

Moritz, S., Birkner, C., Kloss, M., Jahn, H., Hand, I., Haasen, C., \& Krausz, M. (2002). Executive functioning in obsessive-compulsive disorder, unipolar depression, and schizophrenia. Archives of Clinical Neuropsychology, 17, 477-483.

Morris, R.G., Evendon, J.I., Sahakian, B.J., \& Robbins, T.W. (1987). Computer-aided assessment of dementia: Comparative studies of neuropsychological deficits in alzheimer-type dementia and Parkinson's disease. Oxford, UK: Oxford University Press.

Müller, J., \& Roberts, J.E. (2005). Memory and attention in obsessive-compulsive disorder: A review. Journal of Anxiety Disorders, 19, 1-28. doi:10.1016/j.janxdis.2003.12.001

Nakao, T., Nakagawa, A., Nakatani, E., Nabeyama, M., Sanematsu, H., Yoshiura, T., ... Kanba, S. (2009). Working memory dysfunction in obsessive-compulsive disorder: A neuropsychological and functional MRI study. Journal of Psychiatric Research, 43, 784-791. doi:10.1016/j.jpsychires.2008.10.013

Nedeljkovic, M., Kyrios, M., Moulding, R., Doron, G., Wainwright, K., Pantelis, C., ... Maruff, P. (2009). Differences in neuropsychological performance between subtypes of obsessivecompulsive disorder. The Australian and New Zealand Journal of Psychiatry, 43, 216-226. doi:10.1080/00048670802653273 
Nielen, M.M.A., \& Den Boer, J.A. (2003). Neuropsychological performance of OCD patients before and after treatment with fluoxetine: Evidence for persistent cognitive deficits. Psychological Medicine, 33, 917-925. doi:10.1017/s0033291703007682

Okasha, A., Rafaat, M., Mahallawy, N., El Nahas, G., El Dawla, A.S., Sayed, M., \& El Kholi, S. (2000). Cognitive dysfunction in obsessive-compulsive disorder. Acta Psychiatrica Scandinavica, $101,281-285$.

Olley, A., Malhi, G., \& Sachdev, P. (2007). Memory and executive functioning in obsessive-compulsive disorder: A selective review. Journal of Affective Disorders, 104, 15-23. doi:10.1016/j.jad.2007.02.023

Omori, I.M., Murata, Y., Yamanishi, T., Nakaaki, S., Akechi, T., Mikuni, M., \& Furukawa, T.A. (2007). The differential impact of executive attention dysfunction on episodic memory in obsessive-compulsive disorder patients with checking symptoms vs. those with washing symptoms. Journal of Psychiatric Research, 41, 776-784. doi:10.1016/j.jpsychires.2006.05.005

Page, L.A., Rubia, K., Deeley, Q., Daly, E., Toal, F., Mataix-Cols, D., ... Murphy, D.G.M. (2009). A functional magnetic resonance imaging study of inhibitory control in obsessive-compulsive disorder. Psychiatry Research-Neuroimaging, 174, 202-209. doi:10.1016/j.pscychresns.2009.05.002

Penades, R., Catalan, R., Rubia, K., Andres, S., Salamero, M., \& Gasto, C. (2007). Impaired response inhibition in obsessive compulsive disorder. European Psychiatry, 22, 404-410. doi:10.1016/j.eurpsy.2006.05.001

Preacher, K.J, \& Hayes, A.F. (2008). Asymptotic and resampling strategies for assessing and comparing indirect effects in multiple mediator models. Behavior Research Methods, 40, 879-891. doi:10.3758/BRM.40.3.879

Purcell, R., Maruff, P., Kyrios, M., \& Pantelis, C. (1998a). Cognitive deficits in obsessivecompulsive disorder on tests of frontal-striatal function. Biological Psychiatry, 43, 348-357. doi:10.1016/s0006-3223(97)00201-1

Purcell, R., Maruff, P., Kyrios, M., \& Pantelis, C. (1998b). Neuropsychological deficits in obsessivecompulsive disorder: A comparison with unipolar depression, panic disorder, and normal controls. Archives of General Psychiatry, 55, 415-423. doi:10.1001/archpsyc.55.5.415

Salthouse, T.A., Berish, D.E., \& Siedlecki, K.L. (2004). Construct validity and age sensitivity of prospective memory. Memory and Cognition, 32, 1133-1148.

Sanavio, E. (1988). Obsessions and compulsions: The Padua inventory. Behaviour Research and Therapy, 26, 169-177. doi:10.1016/0005-7967(88)90116-7

Schnitzspahn, K.M., Stahl, C., Zeintl, M., Kaller, C.P., \& Kliegel, M. (2013). The role of shifting, updating, and inhibition in prospective memory performance in young and older adults. Developmental Psychology, 49, 1544-1553. doi:10.1037/a0030579

Shallice, T. (1982). Specific impairments of planning. Philosophical Transactions of the Royal Sociey of London, Series B, Biological Sciences, 298, 199-209.

Shimamura, A.P, Janowsky, J.S., \& Squire, L.R. (1991). What is the role of frontal lobe damage in memory disorders? In H.S. Levin, H.S. Eisenberg \& A. Benton, L (Eds.), Frontal lobe function and dysfunction (pp. 173-195). New York: Oxford University Press.

Smith, R.E. (2003). The cost of remembering to remember in event-based prospective memory: Investigating the capacity demands of delayed intention performance. Journal of Experimental Psychology: Learning, Memory and Cognition, 29, 347-361.

Smith, R.E., \& Bayen, U.J. (2004). A multinomial model of event-based prospective memory. Journal of Experimental Psychology: Learning, Memory and Cognition, 30, 756-777. doi:10.1037/0278-7393.30.4.756

Smith, R.E., \& Bayen, U.J. (2005). The effects of working memory resource availability on prospective memory: A formal modeling approach. Experimental Psychology, 52, 243-256. doi:10.1027/1618-3169.52.4.243

Sottocorno, S., Martoni, R., Galimberti, E., Fadda, E., \& Bellodi, L. (2011). P01-150 - Response inhibition in the obsessive-compulsive spectrum. Paper presented at the European Congress of Psychiatry. Retreived from http://www.sciencedirect.com/science/article/pii/S0924933811718612 
Spinella, M. (2005). Mood in relation to subclinical obsessive-compulsive symptoms. International Journal of Neuroscience, 115, 433-443. doi:10.1080/00207450590522838

Stein, D.J. (2002). Obsessive-compulsive disorder. The Lancet, 306, 397-405.

Tabachnick, B.G., \& Fidell, L.S. (2007). Using multivariate statistics (5th ed.). Boston: Pearson International Editing.

Taner, Y.I., Bakar, E.E., \& Oner, O. (2011). Impaired executive functions in paediatric obsessive-compulsive disorder patients. Acta Neuropsychiatrica, 23, 272-281. doi:10.1111/j.1601-5215.2011.00562.x

van den Heuvel, O.A., Veltman, D.J., Groenewegen, H.J., Cath, D.C., van Balkom, A., van Hartskamp, J., . . . van Dyck, R. (2005). Frontal-striatal dysfunction during planning in obsessivecompulsive disorder. Archives of General Psychiatry, 62, 301-310. doi:10.1001/archpsyc.62.3.301

Van der Linden, M., Ceschi, G., Zermatten, A., Dunker, D., \& Perroud, A. (2005). Investigation of response inhibition in obsessive-compulsive disorder using the Hayling task. Journal of the International Neuropsychological Society, 11, 776-783. doi:10.1017/s1355617705050927

Veale, D.M., Sahakian, B.J., Owen, A.M., \& Marks, I.M. (1996). Specific cognitive deficits in tests sensitive to frontal lobe dysfunction in obsessive-compulsive disorder. Psychological Medicine, 26, 1261-1269.

Watkins, L.H., Sahakian, B.J., Robertson, M.M., Veale, D.M., Rogers, R.D., Pickard, K.M., ... Robbins, T.W. (2005). Executive function in Tourette's syndrome and obsessive-compulsive disorder. Psychological Medicine, 35, 571-582. doi:10.1017/s0033291704003691

West, R., \& Craik, F.I. (2001). Influences on the efficiency of prospective memory in younger and older adults. Psychology and Aging, 16, 682-696.

West, R., Scolaro, A.J., \& Bailey, K. (2011). When goals collide: The interaction between prospective memory and task switching. Canadian Journal of Experimental Psychology, 65, 38-47. doi: $10.1037 / \mathrm{a} 0022810$ 